\title{
Kaposi's Sarcoma: An Unusual Cause of Gastric Outlet Obstruction
}

\author{
Sandra Rodriguez, $\mathrm{MD}^{1}$, Jorge Zapatier, $\mathrm{MD}^{2}$, Daniela Allende, $\mathrm{MD}^{3}$, and Alison Schneider, $\mathrm{MD}^{2}$ \\ ${ }^{1}$ Department of Internal Medicine, Cleveland Clinic, Weston, FL \\ ${ }^{2}$ Department of Gastroenterology, Cleveland Clinic, Weston, FL \\ ${ }^{3}$ Department of Pathology, Cleveland Clinic, Weston, FL
}

\begin{abstract}
Kaposi's sarcoma (KS) is the most common AIDS-related neoplasm and is one of the AIDS-defining illnesses. It most frequently presents with cutaneous lesions, but may also involve organ systems. Most cases of gastrointestinal (GI) involvement are clinically silent and found incidentally on imaging studies or endoscopy. Sole involvement of the GI tract can be seen with or without cutaneous disease; however, the latter has been reported as rare by some investigators. We report a case of a 25-year-old man with HIV who presented with gastric outlet obstruction (GOO) and disseminated Gl involvement by KS.
\end{abstract}

\section{Introduction}

AIDS-related Kaposi's sarcoma (KS) is the most common neoplasm in patients infected with HIV. The incidence has significantly decreased since the introduction of highly active anti-retroviral therapy (HAART). Skin involvement is the most common initial presentation, and it is seen in up to $60 \%$ of cases. Visceral involvement is also frequent, affecting most commonly the gastrointestinal (GI) tract (40\%) and lungs (30\%). ${ }^{1,4,6}$ As reported in the literature, the association between gastrointestinal KS and cutaneous disease is controversial. Some studies report the incidence to be as high as 40-70\%.1,5,9 However, other authors have found the former association to be uncommon. ${ }^{3,7,8}$ In the Gl tract, the small intestine is affected most frequently, followed by the stomach, esophagus, and colon, and generally is considered to be more common in the upper gastrointestinal tract than in the lower gastrointestinal tract. 2,3,6

Most patients with Gl involvement are asymptomatic, but may present with non-specific symptoms such as weight loss, diarrhea, and abdominal pain. Endoscopically, lesions range from minimally elevated submucosal vascular patches, some with central ulceration, to large polypoid defects. Obstruction, perforation, intussusception, and protein-losing enteropathy are infrequent complications associated with advance disease and high Gl burden. ${ }^{4,8} \mathrm{KS}$ usually responds to HAART; nevertheless, systemic chemotherapy may be used for symptomatic visceral KS.

\section{Case Report}

A 25-year-old African-American man with history of sexual encounters with men was evaluated in the emergency department for worsening nausea, vomiting, and epigastric abdominal pain for the past 5 days. He had also experienced a 30-pound weight loss over the past 3 months. Vital signs were remarkable for a sinus tachycardia, hypotension, and positive orthostatic blood pressure. Physical examination revealed dry mucous membranes, decreased skin turgor, and no rashes. There was tenderness to palpation in the epigastrium and hyperactive bowel sounds. Laboratory data showed a mild leucopenia and normocytic anemia, but was otherwise unremark-

ACG Case Rep J 2013;1(1):19-21. doi:10.14309/crj.2013.9. Published online: October 8, 2013.

Correspondence: Sandra Rodriguez, MD, Cleveland Clinic Florida, 2950 Cleveland Clinic Blvd, Weston, FL 33331 (rodrigs3@ccf.org)

Copyright: (C) 2013 Rodriguez et al. This is an open-access article distributed under the terms of the Creative Commons Attribution License, which permits unrestricted use, distribution, and reproduction in any medium, provided the original author and source are credited. 
able. Contrast computed tomography (CT) of the abdomen and pelvis revealed multiple nodules in the stomach with marked thickening of the antrum, suggestive of a gastric outlet obstruction (Figure 1). The patient was admitted for conservative management of the obstruction with NPO and intravenous hydration. Gastroenterology was consulted and EGD and colonoscopy were performed, which revealed multiple erythematous nodules with central ulceration through-

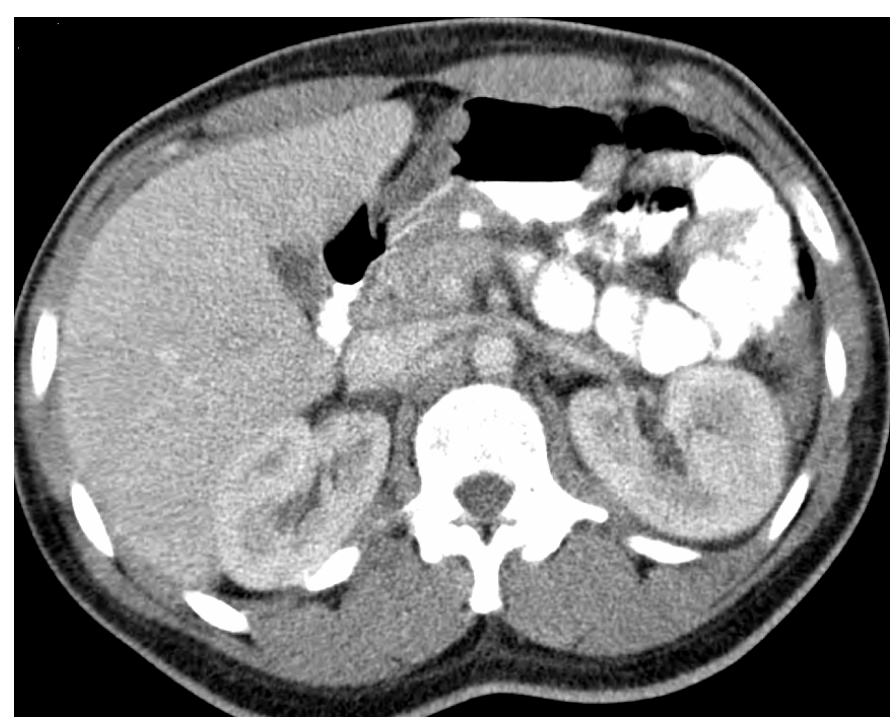

Figure 1. CT of the abdomen showing multiple nodules in the stomach with marked thickening of the antrum, suggestive of gastric outlet obstruction.

out the esophagus, stomach, duodenum, and colon (Figure 2). The largest lesion was located at the lesser curvature of the stomach near the pre-pyloric region. The biopsies revealed gastric mucosa infiltrated by an atypical spindle cell proliferation, forming slit-like vascular spaces, with focally extravasated red blood cells and hemosiderin deposition. The vascular proliferation was strongly and diffusely positive for CD34 and human herpes virus-8 (HHV8; Figure 3). Such

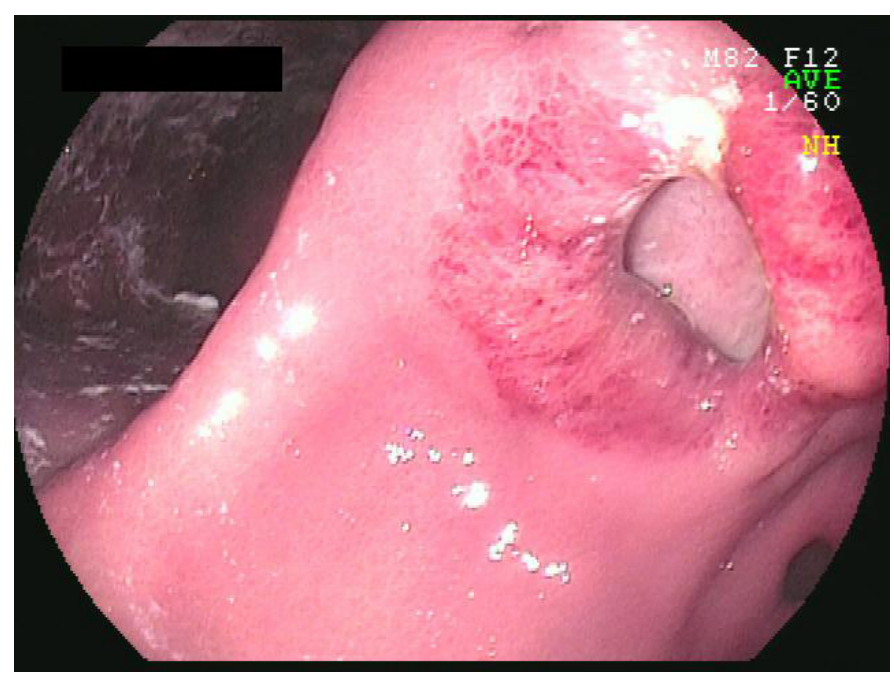

Figure 2. Endoscopic lesions related to Kaposi's sarcoma. histologic and immunohistochemical findings are consistent with Gl involvement by KS.

Upon further testing, he was found to have a CD4 count of 17 cells/ $\mu \mathrm{L}$ and an HIV viral load of 179,000 copies/mL. HAART was initiated, as well as treatment with anthracycline chemotherapy. He completed 6 cycles of taxol over a period of 5 months post initial diagnosis. To date, he has not experienced symptomatic recurrence of his GI symptoms and has achieved adequate virological response.

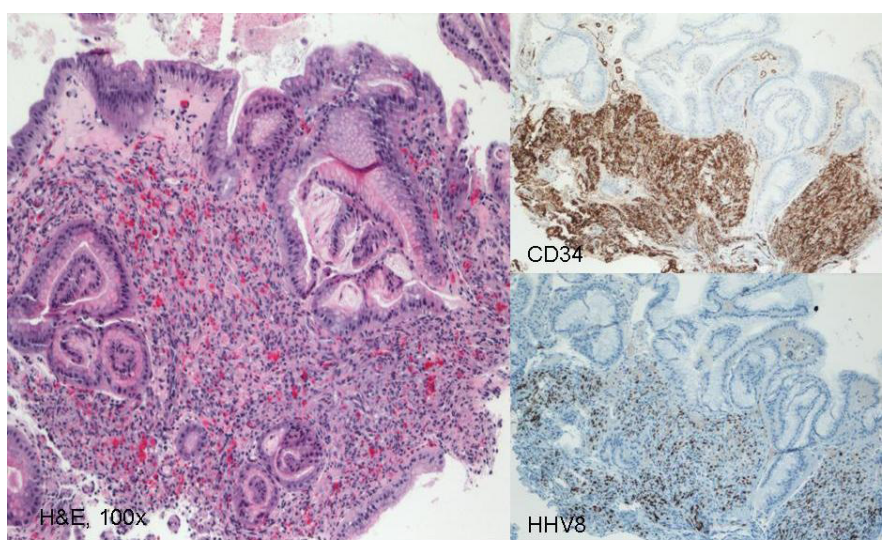

Figure 3. Immunohistochemical stains diffusely positive for human herpes virus-8 (HHV-8) and CD-34, confirming the diagnosis of diffuse visceral Kaposi's sarcoma.

\section{Discussion}

We present a case of KS with diffuse gastrointestinal involvement in the absence of cutaneous disease that manifested with acute gastric outlet obstruction. To our knowledge, this is a very infrequent initial presentation of AIDS, as most patients with KS and GI involvement have no Gl symptoms. Our goal is to encourage clinicians maintain a high index of suspicion in high-risk patients who present with persistent Gl symptoms, even in the post-HAART era. In addition, we recommend early endoscopic evaluation to prevent complications associated with progression of the disease. This will allow for proper staging and selection of the appropriate therapeutic options.

\section{Disclosures}

Author contributions: S. Rodriguez wrote and revised the article, performed the literature search, and is the article guarantor; J. Zapatier wrote and revised the article, and performed the literature search; D. Allende provided the pathological descriptions, histology, and images; A. Schneider initially conceptualized and revised the article.

Financial disclosures: None of the authors have any financial or other conflict of interest.

Received: May 17, 2013; Accepted: August 26, 2013 


\section{References}

1. Saltz RK, Kurtz RC, Lightdale CJ, et al. Kaposi's sarcoma. Gastrointestinal involvement correlation with skin findings and immunologic function. Dig Dis Sci. 1984;29(9):817-23.

2. Friedman SL, Wright TL, Altman DF. Gastrointestinal Kaposi's sarcoma in patients with acquired immunodeficiency syndrome. Gastroenterology. 1985;89(1):102-8.

3. Parente F, Cernuschi M, Orlando G, et al. Kaposi's sarcoma and AIDS: Frequency of gastrointestinal involvement and its effect on survival. A prospective study in a heterogeneous population. Scand J Gastroenterol. 1991;26(10):1007-12.

4. Weprin L, Zollinger R, Clausen K, Thomas FB. Kaposi's sarcoma: Endoscopic observation of gastric and colon involvement. J Clin Gastroenterol. 1982;4:357-60.

5. Zoller WG, Bogner JR, Liess $\mathrm{H}$, et al. Diagnosis and therapy of gastrointestinal Kaposi's sarcoma in AIDS. Bildgebung. 1994;61(suppl 1):46-52.

6. Reed WB, Kamath HM, Weiss L. Kaposi's sarcoma with emphasis on internal manifestations. Arch Dermatol. 1974;110(1):115-8.

7. Yee J, Wall SD. Gastrointestinal manifestations of AIDS. Gastroenterol Clin North Am. 1995;24(2):413-34.

8. Gottlieb MS, Groopman JE, Weinstein WM, et al. The acquired immunodeficiency syndrome. Ann Intern Med. 1983;99(2):208-20.

9. Barrison IG, Foster S, Harris JW, et al. Upper gastrointestinal Kaposi's sarcoma in patients positive for HIV antibody without cutaneous disease. Br Med J (Clin Res Ed). 1988;296 92-93.

\section{Publish your work in ACG Case Reports Journal}

ACG Case Reports Journal is a peer-reviewed, open-access publication that provides Gl fellows, private practice clinicians, and other members of the health care team an opportunity to share interesting case reports with their peers and with leaders in the field. Visit http://acgcasereports.gi.org for submission guidelines. Submit your manuscript online at http://mc.manuscriptcentral.com/acgcr. 